\title{
Terrorism, distress and coping: High versus low impact regions and direct versus indirect civilian exposure
}

\author{
ELI SOMER ${ }^{1,2,3}$, AYALLA RUVIO $^{4}$, EREZ SOREF $^{2,5}, \&$ ILANA SEVER ${ }^{2,6}$ \\ ${ }^{1}$ School of Social Work, University of Haifa, ${ }^{2}$ Maytal - Israel Institute for Treatment and Study of \\ Stress, ${ }^{3}$ R. D. Wolfe Centre for the Study of Psychological Stress, ${ }^{4}$ Graduate School of Business, \\ University of Haifa, ${ }^{5}$ Department of Gerontology, University of Haifa, ${ }^{6}$ School of Education, University \\ of Haifa, Israel
}

(Received 27 April 2004; revised 6 October 2004; accepted 28 May 2005)

\begin{abstract}
The 2001-2002 terror campaign against Israel's heartland was an unprecedented string of deadly bombing attacks against Israeli civilians. The violence touched the lives of countless Israelis and has negatively affected the general mood of many. The objective of this investigation was to assess the level of exposure to terrorism for individuals residing in the affected areas and to examine psychological responses and ways of coping during the peak of the violence. A random sample of 327 adults, purposely over-sampled from the hardest-hit areas, was surveyed. Although citizens residing in the most severely hit locales were also those who suffered most from posttraumatic symptoms, the effects of major national trauma were not limited to those directly exposed to it. These results suggest that objective measures of exposure or loss may not be sensitive predictors of reactive distress. Acceptance of the situation and its uncontrollability was both the most commonly used way of coping employed and the only effective one.
\end{abstract}

Keywords: Terror, stress, coping, Israel

With approximately 3000 fatalities in New York City alone, the attacks of September 2001 represented the largest single act of terrorism in history. Although the nature of this isolated, sudden and astounding event is qualitatively different from the repeated chronic terrorism Israelis have been subjected to, recently published data about the aftermath of that attack shed light on the impact of terrorism worldwide. Data from a nationally representative sample of 569 US adults contacted 3-5 days after September 11, indicated that people who were not present at a traumatic event may also experience stress reactions (Schuster et al., 2001). This study revealed that $44 \%$ of the adults reported one or more substantial stress symptoms, $47 \%$ were worried about their own safety or the safety of loved ones. Respondents coped by talking with others (98\%), turning to religion (90\%), participating in group activities (60\%), and making donations (36\%). In a web-based epidemiological survey of a nationally representative cross-sectional sample administered 1 to 2 months following the September 11 attacks, (probable) Post Traumatic Stress Disorder (PTSD)

Correspondence: Eli Somer, School of Social Work, University of Haifa, Mt. Carmel, Haifa 31905, Israel. E-mail: somer@research.haifa.ac.il 
was found not only in $11.2 \%$ of NYC residents, but also in $2.7 \%-4 \%$ of those living in other parts of the country. Risk factors for PTSD included age, sex and the number of hours of television coverage viewed (Schlenger et al., 2002). The vulnerability of citizens residing far from the impact area following a major national trauma was also documented by Cohen Silver, Holman, McIntosh, Poulin, and Gil-Rivas (2002). They reported that $17 \%$ of US citizens, outside New York City, suffered from a posttraumatic stress syndrome 2 months after the attack, and $5.8 \%$ were still showing symptoms 6 months following the attack. They found that disengaging from coping efforts can signal the likelihood of psychological difficulties up to 6 months after a trauma. Based on reviewed studies, Gidron (2002) concluded that the prevalence of PTSD after terrorist attacks worldwide is estimated to be approximately $28 \%$.

\section{Background}

Over 1000 Israelis have been killed in the "Al-Aqsa Intifada", a prolonged series of terror attacks that included shooting incidents, car bombings and suicide bomb attacks. In a country of 6.5 million inhabitants, this casualty rate was massive. Countless others were physically and psychologically injured. Since the eruption of this campaign and the collection of data for this study, 653 attacks had been launched against Israeli civilians. Television, radio, internet and printed media coverage of these events was immediate, graphic, and extensive, contributing to a sense of a massive shared national crisis that engulfed survivors and other civilians alike. Terrorists struck in many towns and cities but mostly concentrated on the three major metropolitan areas: Jerusalem, Tel Aviv and Haifa; and three smaller cities adjacent to the Palestinian-Israeli Green Line (the unofficial border): Hadera, Netanya and Afula. At a peak of this violence in an extended string of hostilities, we decided to interview citizens residing in the areas most highly affected by the terrorists' violence.

Recent evidence leads trauma scholars to conceptualize the lasting psychological effects of indirect exposure to mass violence (for example, seeing it in real time on TV or knowing someone indirectly who was lost or who suffered). Although studies suggest that physical proximity to traumatic events is related to a greater likelihood of experiencing traumatic symptoms (e.g., Schelenger et al., 2002; Schuster et al., 2001), people who do not experience the event directly also may report stress reactions (e.g., Pfeferbaum et al., 2001). The terrorist attacks in Oklahoma and on the World Trade Centers have resulted in several psychiatric epidemiological research projects (e.g., Pfefferbaum, Moore et al., 1999; Pfefferbaum, Nixon et al., 1999; Pfefferbaum et al., 2001; Galea et al., 2002; Schlenger et al., 2002; Schuster et al., 2001). Taken together, the data from these large-scale telephone interview surveys suggest that exposure to emotionally charged, real-life television images of death and destruction can produce symptoms of PTSD and depression in children and adults. This phenomenon has been referred to in the trauma literature as "vicarious traumatization". While there has been some debate about how these concepts differ (Jenkins \& Baird, 2002), we studied vicarious traumatization by assessing post-traumatic stress reactions also among those who had not been present on site during a terror attack. Our assumption was that many Israeli citizens outside the terror-stricken zones had been exposed to the extensive traumatizing sounds and images broadcast on national radio and television. Others had been indirectly exposed through affected friends or family members.

Whereas Bleich, Gelkopf, and Solomon (2003) assessed exposure to terrorism, symptoms, and coping with terrorism in a nationally representative sample of Israelis, we investigated the impact of terrorism on Israelis residing in the most severely targeted areas and compared 
those results with those of a group sampled in an unaffected part of the country. We decided to focus on indicators of post-traumatic stress because we wanted to gauge the most commonly studied psychological outcome of trauma and disasters (Galea et al., 2002; Lomranz, Hobfoll, Johnson, Eyal, \& Zemach, 1994; Resnick, Kilpatrick, Dansky, Saunders, \& Best, 1993). Measurement of non-pathological distress was seen as a more adequate index of the psychological status of demoralized populations under threat (North \& Pfefferbaum, 2002; Yagur, Grinshpoon, \& Ponizovsky, 2002). We therefore also attempted to assess nonpathological distress (or mood, i.e., sadness and tension) among our respondents.

In addition to our assessment of the extent of exposure to acts of terrorism, coping strategies employed, and the psychological outcome of these events, we also hypothesized that:

1. because of extensive coverage of terrorism in the national media and the small size of the country, individuals living in regions that have never been exposed directly to terrorist violence would also be affected emotionally.

2. We predicted that individuals residing in areas highly affected by terrorist violence would show higher levels of psychological distress than respondents living outside the high-impact regions.

3. We also expected that individuals directly exposed to acts of terrorism would show levels of psychological distress higher than individuals indirectly exposed.

4. We further anticipated that individuals residing in areas where terrorism struck most severely would employ coping behaviours more extensively than individuals who reside in more remote parts of the country, and that

5. Respondents that were directly exposed to terrorist violence would, likewise, report higher levels of coping behaviours than those who were not directly exposed to terror.

\section{Method}

\section{Procedure}

Six research assistants received training to ensure standardized administration of the research instruments. These individuals were all college educated; three were graduate students. All had prior experience with research assistance. The interviewers also used written scripts to introduce the survey and its various components. Because the interview process only involved reading aloud from printed statements and questions, optimal standardization was achieved during a single 3-hour training session. To ensure fidelity we conducted random checks of the interviewing process. Quality of administration of the research protocol was generally very good. Corrective feedback was offered on the rare occasions when minor modifications in the interviewing style were warranted. In addition, one researcher was permanently on call during data collection to resolve specific dilemmas as they arose. A computer-generated random telephone list for citizens in the three major cities (Jerusalem, Tel Aviv and Haifa) and the three most highly affected smaller cities (Afula, Hadera and Netanya) was used (Telepathy Software, Survey Version, courtesy of Dvash Software Systems, Israel). Using the same sampling method, we also produced a list of individuals in the remote, never attacked, southern resort city of Eilat. The research assistants were instructed to call consecutive numbers on the list until they were answered. Israel has recently attracted many immigrants from the former Soviet Union and from Ethiopia. Because of budgetary constraints, we were unable to hire and train a multi-lingual research assistance team. We therefore instructed our assistants to interview only Hebrew 
speaking individuals who were consenting adults (over 18-years-old). Because most immigrants attend subsidized Hebrew courses shortly after their arrival, we assumed that this criterion would exclude only a relatively small number of very recently arrived individuals. The volatile situation in Israel during data collection warranted a rapid collection of data to ensure equivalence in terms of participant exposure to terrorism and what had been reported in the media. Data for this study was, therefore, collected without interruption for two consecutive weeks during the month of April 2002, 1 month after the especially severe events of March 2002, in which 81 civilians were killed in 11 separate suicide attacks.

\section{Participants}

During the 2-week period of data collection, 602 calls were made, of which 545 were answered by respondents who met our inclusion criteria. The other 57 phone calls were either not answered, disconnected, bad connections, answered by non-Hebrew speaking immigrants, or by minors. We excluded seven Hebrew speaking minors, ten Russian speaking adults (seven women, three men) and five adults (four women, one man) who answered in Hebrew that they did not speak the language. The final sample totalled 327 subjects who gave verbal consent to participate in this research project, representing a $60 \%$ response rate. There were no differences in response rates across the sampling zones. Although a higher response rate would have been desirable, this outcome is in line with previous findings that the mean response rate among surveys published on health research and service data was also approximately 60\% (Asch, Jedrziewski, \& Christakis, 1997; Smith, Chey, Jalaudin, Salkeld, \& Capon, 1995). To assess the similarity of our sample to the general Israeli population we consulted the Statistical Abstract of Israel (2002). The average age of the respondents was 42.5 years, which was almost identical to the average in the general Israeli population (42.4). Our average respondent had 13.6 years of education compared to 13.1 years of education that characterized Israelis of similar age. The gender ratio of respondents in this study was $60 \%$ women and $40 \%$ men (see Table I), which is somewhat higher than that of the general population ( $51 \%$ women, $49 \%$ men). Nevertheless, no statistically significant differences between the sexes were found in terms of age, level of education, or ethnicity. More men in the sample were single.

\section{Measures}

The measures for this study were compiled to form a structured interview designed to address our specific research questions. The following domains were investigated: (1) demographic information; (2) exposure to terror attacks; (3) modes of coping; (4) mood; (5) trauma/PTSD symptoms; (6) shifts in political views. Previous experience with peritraumatic research in Israel has taught us that if respondent drop-out is to be minimized, telephone interviews with citizens under the strain of military threats cannot last more than 30 minutes (Somer, Keinan, \& Carmil, 1996). The design of our study instruments reflects efforts to obtain optimal balance between accuracy and brevity.

Demographic information. Demographic data included age, gender, marital status, number of children, country of origin, year of immigration, city of residence, and level of education.

Index of Exposure to Terror (IET). The IET included several aspects of exposure to terror in Israel. We asked respondents "yes or no" questions about the terror attacks that had taken 
Table I. Demographic characteristics of the sample $(\mathrm{N}=327)$.

\begin{tabular}{|c|c|c|c|c|c|c|c|c|c|c|c|c|c|c|c|c|c|c|c|c|c|}
\hline & \multicolumn{3}{|c|}{ Total } & \multicolumn{3}{|c|}{$\begin{array}{c}\text { Men } \\
(n=128)\end{array}$} & \multicolumn{3}{|c|}{$\begin{array}{l}\text { Women } \\
(n=198)\end{array}$} & \multirow[b]{2}{*}{$\mathrm{df}$} & \multirow[b]{2}{*}{$\chi^{2}$} & \multirow[b]{2}{*}{$t$} & \multicolumn{3}{|c|}{$\begin{array}{l}\text { Low Impact Region } \\
\qquad(n=54)\end{array}$} & \multicolumn{3}{|c|}{$\begin{array}{l}\text { High Impact Region } \\
\qquad(n=273)\end{array}$} & \multirow[b]{2}{*}{$\mathrm{df}$} & \multirow[b]{2}{*}{$\chi^{2}$} & \multirow[b]{2}{*}{$t$} \\
\hline & $M$ & SD & $\%$ & M & SD & $\%$ & M & SD & $\%$ & & & & M & SD & $\%$ & M & SD & $\%$ & & & \\
\hline Age & 42.5 & 15.6 & & 41.6 & 15.7 & & 43.2 & 15.6 & & 324 & & -0.9 & 40.4 & 13.7 & & 42.9 & 16.0 & & & & -1.1 \\
\hline \multicolumn{22}{|l|}{ Region } \\
\hline Low impact & & & & & & 56.6 & & & 43.4 & & & & & & & & & & & & \\
\hline high impact & & & & & & 35.9 & & & 64.1 & & & & & & & & & & & & \\
\hline Education & 13.6 & 2.9 & & 13.1 & 2.5 & & 13.7 & 3.1 & & 292.7 & & -1.7 & 12.7 & 2.1 & & 13.6 & 3.0 & & & & $-2.1^{\star}$ \\
\hline Marital Status & & & & & & & & & & 1.0 & $4.0^{\star}$ & & & & & & & & 1 & 1.4 & \\
\hline single & & & 35 & & & 41.7 & & & 30.8 & & & & & & 25.9 & & & 23.9 & & & \\
\hline married & & & 65 & & & 58.3 & & & 69.2 & & & & & & 64.1 & & & 66.1 & & & \\
\hline Ethnicity & & & & & & & & & & 1.0 & 0.5 & & & & & & & & 1 & 1.3 & \\
\hline Israeli-Born & & & 57.2 & & & 58.1 & & & 56.6 & & & & & & 64.8 & & & 55.7 & & & \\
\hline Non-Israeli-Born & & & 42.8 & & & 41.9 & & & 43.4 & & & & & & 35.2 & & & 44.3 & & & \\
\hline
\end{tabular}

Note: ${ }^{\star} p<0.05$. 
place during the Al-Aqsa Intifada (with follow-up open-ended questions for questions answered in the affirmative): Direct/Objective Exposure to Terror was measured by answers to the following three questions: (1) "Were you present on site during a terror attack? (e.g., a shooting, a bombing)"; (2) "Have you been exposed to a terror event as a member of an early response team, or as a reservist with the Israel Defense Forces?" (3) "Have you been injured physically during a terror attack?". We also inquired about Indirect and Subjective Exposure to the Threat of Terror with the following questions: (1) "Have you provided either physical or emotional aid to a terrorism victim?" (2) "Have you passed by a terror attack scene shortly after the event and witnessed signs of carnage and/or property damage?" (3) "Do you personally know somebody who was on site during a terror attack?" (4) "Do you feel you have escaped a terror attack by luck or by coincidence (e.g., missed your bus only to find out it was destroyed minutes later by a suicide bomber)?"

Based on this information, we divided our sample into two groups: 54 people who answered "yes" to one of the three direct exposure questions, and thus reported objective exposures to terror, and 273 people who did not answer "yes" to any of these questions, and reported only subjective exposures to terror.

Coping with Terror Scale (CTS). Although it was evident that the series of unrelenting terror attacks created a unique condition to which Israelis reacted with distinct ways of coping (e.g., planning escape routes when dining out) no other specific coping scales were readily available at the time. Lazarus developed the Ways of Coping Checklist (WCC) in the 1970s. It was based on the transactional model of stress, which posited two types of coping: problem-focused and emotional regulation (Lazarus, 1991). This instrument has always had a drawback: the number of factors obtained changes from one sample to the next or from one stressor to another (Parker \& Endler, 1992). This common problem with measurement of coping underscores an unresolved issue: disposition versus situation. In order to attain maximum pairing between stress experiences and types of coping, we prudently attempted to adjust the measurement of coping to the specific context of the AlAqsa Intifada by developing an instrument that was more pertinent to the specific circumstances of the situation. The items comprising the CTS were based on the outcome of focus groups (Krueger, 1994; Linhorst, 2002; Spradely, 1979) facilitated by the first author with 16 Israeli citizens residing in one of the terror-afflicted cities, concerning their particular ways of coping with the threat of terrorist attacks. Focus groups are usually composed of 6 to 12 participants (Morgan, 1988; Stewart \& Shamdasani, 1990). Our groups included seven graduate students (four women, three men; 25-38-years-old) and nine university employees (six women, three men; 28-48-years-old). All participants were residents of terror stricken towns, and therefore, representative of the targeted population. One basic research question was the focus during group discussion: "What are you doing that helps you cope with the current threat of terrorist attacks?" The group interviews lasted between 50 minutes and 1.5 half hours. The researcher-moderator took notes during the discussion to record the various coping strategies described by the participants. The second focus group yielded no novel coping items. It was, therefore, concluded that saturation had been reached. Analysis of the participants' materials yielded ten coping tactics that comprised the final instrument: (1) direct action/confrontational coping (I took direct action, for example: purchased a handgun); (2) planning (I devised various survival plans, for example: by choosing the safest seats in a bus or a restaurant); (3) distraction/mental disengagement (I watched a lot of movies or sitcoms); (4) self-care (I engaged in sports, yoga, improved nutrition); (5) restraint coping (I stopped going out to public places); (6) 
seeking social interaction (I spent more time talking with friends and relatives); (7) behavioural disengagement from stressful cues (I watched/read the news less); (8) acceptance (I learned to live with the situation); (9) turning to God (I turned to God); (10) ignoring the situation (I lived as if nothing was happening). Respondents to the Telephone survey were asked to indicate how much each statement reflected their coping tactics during the month of March 2002, ranging from 1 "not at all" to 5 "very much". Cronbach's alpha for this heterogeneous scale was 0.66 .

After ensuring content validation, we also conducted an exploratory factor analysis to detect internal structure and relationships between the coping variables. Of the ten items, two were dropped (Items 9 and 10) from the analysis due to low reliability values (e.g., a widely endorsed item that did not differentiate between groups) and were not included in the factor analysis. A Principal Component Analysis was conducted using the Varimax rotation method with Kaiser Normalization. Three factors were extracted: Problem-solving Coping (Items 1, 2, 5, and 6; $\alpha=0.61$ ), Emotion-focused Coping (Items 7, 3, and 4; $\alpha=$ 0.57 ) and Acceptance (Item 8), an assessment-focused way of coping; explaining about $66 \%$ of the total variance, with factor loadings ranging from 0.533 to 0.905 (detailed results can be obtained from the authors). This outcome demonstrates structure validation of this measurement. The factors corresponded with previously formulated concepts about ways of coping (Lazarus \& Folkman, 1980; and Carver, Scheier, \& Weintraub, 1989) and were in line with the dimensions proposed in the model by Billings and Moos (1981; Moos \& Billings, 1982), who divided coping processes into three categories (problem-focused, emotions-focused, and assessment-focused).

The Hebrew Mental Health Inventory (H-MHI). This is the Hebrew version of the Mental Health Inventory-5 (MHI-5; Berwick et al., 1991). To ensure fidelity, the MHI-5 was adapted and translated into Hebrew and then back translated by two bilingual professionals. The MHI-5 performed as well as or better than three lengthier psychopathology screening questionnaires (the 18-item MHI, the 30-item General Health Questionnaire [GHQ], and a 28-item Somatic Symptom Inventory [SSI]). Hanely and McNeil (1982, 1983) showed that the "area under the ROC curve" (AUC) can be taken as a measure of the degree of information the test contains over its entire scoring range. A test with no information has an AUC of 0.5; a perfect test has an AUC of 1.0. Receiver Operating Characteristics (ROC) analysis for the MHI-5 yielded an AUC ranging from 0.739 to 0.892 (Berwick et al., 1991). We regarded the H-MHI-5 as a measure of mood rather than mental health. This tool was chosen as an index of negative mood because of its good psychometric properties and conciseness. The MHI contains five questions assessing sadness, and emotional tension (How much of the time during the past 4 weeks: (1) have you been nervous? (2) Have you felt calm and peaceful? (3) Have you felt down-hearted and blue? (4) Have you been a happy? (5) Have you felt so down in the dumps, that nothing could cheer you up?). The MHI uses a 5-point Likert scale, ranging from (1) "not at all" to (5) "all the time". The NMI demonstrated an internal consistency of Cronbach's alpha $=0.63$. However, when we removed the unreliable Item 4 we obtained a 4 -item H-MHI scale with an internal consistency (Cronbach alpha coefficient) of $\alpha=0.70$. The final 4 -item HMHI was used in this study, with Items 1 and 2 forming the tension index and Items 3 and 5 comprising the sadness index.

The Impact of Event Scale, Revised Version, Brief (IES-R-B). The IES-R (Marmar, Weiss, Metzler, Ronfeldt, \& Forman, 1996; Weiss, Marmar, Metzler, \& Ronfeldt, 1995) is a 
measure designed to fit the DSM-VI symptoms criteria for PTSD. The original instructions provided by Weiss and Marmar (1997) indicate it is intended to measure "difficulties people sometimes have after stressful life events". The instructions given to participants in this study were to indicate how distressing each difficulty has been during the past 7 days with respect to recent terrorist attacks. The questionnaire consists of 22 items, measured on a 4-point Likert scale, ranging from 1 "not at all" to 4 "very much". The IES-R has three sub-scales: avoidance (eight items), intrusion (seven items) and hyperarousal (seven items) and has demonstrated strong psychometric properties (Marmar et al., 1996; Weiss et al., 1995). Following an adaptation, translation and back translation by two bilingual professionals, we adapted 12 of the original 22 questions of the IES-R (hence, IES-R-B) because we had chosen to construct a shorter instrument more suitable for a telephone study. To choose the best items for the abbreviated instrument, we explored a data base collected for a separate study (Somer, Soref \& Lawental, 2004) and identified items with the lowest loading on their respective factors (Intrusion, Avoidance, Hyperarousal). On further inspection, we concluded that these items might have been hindered by conceptual or linguistic equivalence problems (Fouad, 1993; Geisinger, 1994). It has been argued that cross-cultural testing needs to assure that translated instruments are characterized by functional equivalence, conceptual equivalence, and linguistic equivalence (Jeanrie \& Bertrand, 1999; Lonner \& Berry, 1986). Following this procedure we removed three Avoidance items, three Intrusion items, and four Hyperarousal items. The Hebrew version of the IES-R recently showed a Cronbach's reliability coefficient of $\alpha=0.94$ (Somer, Soref \&, Lawental, 2004). Using the same database we found that the shorter IES-R-B had a Cronbach's reliability coefficient of $\alpha=0.88$. Further calculations revealed that Pearson correlations between IES-R-B and IES-R and between IES-R-B and PTSD diagnoses were 0.97 , and 0.88 , respectively, demonstrating the construct validity of the abbreviated instrument. Based on these acceptable reliability and validity data, we decided to adopt the IES-R-B as one of our research instruments. Chronbach's alpha coefficient of the IES-R-B calculated in this study was $\alpha=0.70$.

In addition to the IES-R-B total score and subscales, we also created an additional outcome variable. Because the IES-R-B is an abbreviated tool, and because we wished to assess posttraumatic distress (PTD), not PTSD, we reduced the number of required item endorsements to meet DSM criteria for inclusion in the PTD variables we generated. We created a binary Severe PTD score, a possible PTSD "caseness" indicator. In this group we included individuals who scored 4 or 5 (out of 5) on at least one intrusion item (One intrusion item is required in the DSM criteria for PTSD), at least two avoidance items (DSM requires at least three) and at least one hyperarousal item (two are required minimally by DSM).

\section{Results}

\section{Exposure to Terror}

Table II presents the number of individuals who reported being exposed to terrorist violence. Almost $10 \%$ of our respondents, sampled mainly from the most severely hit locales in Israel, reported having been personally exposed to terrorism (present on the scene while a terrorist attack was perpetrated), and about $2 \%$ of the sample had been physically injured during such an attack. Over $12 \%$ had provided physical or emotional assistance to a terrorism victim. About $28 \%$ of our respondents were under the impression that they had escaped a terrorist attack only by luck (e.g., walked by the site only minutes before a suicide 
Table II. Number of respondents reporting exposure to terror attacks in low- and high-impact regions.

\begin{tabular}{lccc}
\hline Characteristic & $\begin{array}{c}\text { Low Impact } \\
\text { Region }(n=54)\end{array}$ & $\begin{array}{c}\text { High Impact } \\
\text { Region }(n=273)\end{array}$ & $\begin{array}{c}\text { Total Sample } \\
(n=327)\end{array}$ \\
\hline Present on the scene during a terrorist attack & 6 & 26 & 32 \\
Present on site as a first responder & - & - & - \\
Physically injured by a terrorist attack & - & 5 & 5 \\
Provided either physical or emotional aid to a terrorism victim & 1 & 41 & 42 \\
Exposed to the damaged site shortly after a terrorism attack & 7 & 111 & 118 \\
Knew somebody who was on site during a terrorist attack & 18 & 127 & 145 \\
Escaped a terrorist attack by luck & 6 & 84 & 90 \\
\hline
\end{tabular}

bomber detonated his charge, missed a bus that was bombed only minutes later, etc.). Over a third of the participants reported exposure to a terrorism-damaged site shortly after the impact, and $44.5 \%$ reported knowing a civilian that was involved in a terrorism attack personally.

Our geographical control sample included some individuals with varying degrees of exposure to terrorism (see Table II) indicating that some persons who had been exposed to terrorism might have been residents of the far south or that people who had been exposed to terrorism had fled south to seek shelter in their vacation apartments in the resort city of Eilat.

\section{Negative mood}

In early 2005, we assessed with a small independent sample the mood of Israelis under more peaceful conditions. The mean $\mathrm{H}-\mathrm{MHI}$ score of 25 consenting individuals randomly surveyed with a telephone interview was 1.93 (on a 5-point Likert scale, SD $=0.79$ ). On the other hand, in the present study sample the mean H-MHI total score at the peak of the terror campaign was 3.07 (above the mid-point of this instrument), suggesting a moderately high level of reported negative mood. To determine the prevalence of severe or extreme levels negative mood we counted those who reportedly experienced the indicated distress most of or all the time (scores 4 or 5 on the $\mathrm{H}-\mathrm{MHI}$ ). About $18 \%$ of the respondents reported highly elevated levels of sadness and $54 \%$ of the respondents reported tension of that magnitude.

Our first hypothesis postulated that individuals living in areas of the country that were not exposed directly to terrorism would also be affected emotionally by it. Comparative data on negative mood in the various subgroups under analysis are presented in Table III. The level of exposure to terrorist violence did not seem to influence the mood of Israelis but did have a significant effect on posttraumatic symptoms. Contrary to our second hypothesis, however, residence outside the terror afflicted regions still seemed to have had a negative effect on mood. These data support the first and third research hypotheses but are not entirely in-line with our second hypothesis, which predicted that individuals residing in areas highly affected by terrorist violence would show higher levels of psychological distress than respondents living elsewhere.

Tables III and IV present means, standard deviations and multivariate analysis of variance (MANOVA) for all the variables under study, objective versus subjective exposure and for high- versus low-impact regions. Although we had only two groups in each analysis, we used an $F$-test procedure that allowed a Bonferroni inequality approach (instead of $t$-test), to help us control for possible Type I errors (Hair Anderson, Tatham, \& Clack, 1998). We ran the analysis using a weighing procedure that calculated the group differences as if the 
Table III. Negative mood and posttraumatic distress (PTD) across levels of exposure to terror and impact regions: Means, standard deviations and differences $(F$-test) $(n=327)$.

\begin{tabular}{|c|c|c|c|c|c|c|c|c|c|c|c|c|}
\hline & \multicolumn{2}{|c|}{$\begin{array}{l}\text { Total Sample } \\
\quad(n=327)\end{array}$} & \multicolumn{2}{|c|}{$\begin{array}{l}\text { Directly Exposed } \\
\quad(n=32)\end{array}$} & \multicolumn{2}{|c|}{$\begin{array}{l}\text { Indirectly Exposed } \\
\quad(n=295)\end{array}$} & \multirow[b]{2}{*}{$\mathrm{F}^{\star}$} & \multicolumn{2}{|c|}{$\begin{array}{l}\text { Low-Impact Region } \\
\qquad(n=54)\end{array}$} & \multicolumn{2}{|c|}{$\begin{array}{l}\text { High-Impact Region } \\
\qquad(n=273)\end{array}$} & \multirow[b]{2}{*}{$\mathrm{F}^{\star}$} \\
\hline & $M$ & SD & $M$ & SD & $M$ & SD & & M & $\mathrm{SD}$ & $M$ & SD & \\
\hline \multicolumn{13}{|l|}{ Negative Mood } \\
\hline Tension & 3.66 & 1.13 & 3.68 & 1.33 & 3.66 & 1.11 & -0.61 & 4.38 & 0.68 & 3.50 & 1.15 & $102.66^{\star \star}$ \\
\hline Sadness & 2.49 & 1.20 & 2.46 & 1.20 & 2.49 & 1.20 & 1.44 & 2.82 & 1.12 & 2.41 & 1.20 & $13.59^{\star \star}$ \\
\hline Total H-MHI & 3.07 & 1.00 & 3.07 & 1.03 & 3.07 & 1.00 & 1.45 & 3.60 & 0.74 & 2.96 & 1.01 & $60.97^{\star \star}$ \\
\hline \multicolumn{13}{|c|}{ Posttraumatic Symptoms } \\
\hline Avoidance & 1.30 & 1.25 & 1.34 & 1.38 & 1.29 & 1.24 & 0.15 & 0.74 & 1.03 & 1.42 & 1.26 & $42.00^{\star \star}$ \\
\hline Intrusion & 2.30 & 1.50 & 3.00 & 1.43 & 2.23 & 1.49 & $33.74^{\star}$ & 2.25 & 1.55 & 2.31 & 1.50 & 0.03 \\
\hline Hyperarousal & 1.13 & 1.28 & 1.77 & 1.83 & 1.07 & 1.20 & $26.51^{\star}$ & 0.73 & 0.93 & 1.21 & 1.33 & $22.89^{\star \star}$ \\
\hline \multirow[t]{2}{*}{ Total IES-R-B } & 1.62 & 1.06 & 2.06 & 1.21 & 0.33 & 0.93 & $23.43^{\star}$ & 1.28 & 0.97 & 1.69 & 1.07 & $17.93^{\star \star}$ \\
\hline & $N$ & $\%$ & $N$ & $\%$ & $N$ & $\%$ & $\chi^{2}$ & $N$ & $\%$ & $N$ & $\%$ & $\chi^{2}$ \\
\hline Severe PTD & 17 & $5.2 \%$ & 2 & $6.3 \%$ & 15 & $5.1 \%$ & 0.08 & 2 & $3.7 \%$ & 15 & $5.5 \%$ & 0.29 \\
\hline
\end{tabular}

Note: ${ }^{\star} p<0.05 ;{ }^{\star \star} p<0.01$. 
Table IV. Ways of coping across level of exposure to terror and impact regions: Means, standard deviations and differences $(\mathrm{F}$-test) $(N=327)$.

\begin{tabular}{|c|c|c|c|c|c|c|c|c|c|c|c|c|}
\hline \multirow[b]{2}{*}{ Coping Tactic } & \multicolumn{2}{|c|}{$\begin{array}{l}\text { Total Sample } \\
\quad(n=327)\end{array}$} & \multicolumn{2}{|c|}{$\begin{array}{l}\text { Directly Exposed } \\
\quad(n=32)\end{array}$} & \multicolumn{2}{|c|}{$\begin{array}{l}\text { Indirectly exposed } \\
\quad(n=295)\end{array}$} & \multirow[b]{2}{*}{$\mathrm{F}$} & \multicolumn{2}{|c|}{$\begin{array}{l}\text { Low-Impact Region } \\
\qquad(n=54)\end{array}$} & \multicolumn{2}{|c|}{$\begin{array}{l}\text { High-Impact Region } \\
\qquad(n=273)\end{array}$} & \multirow[b]{2}{*}{$\mathrm{F}$} \\
\hline & M & SD & M & SD & M & SD & & M & SD & M & SD & \\
\hline Confrontive coping & 3.08 & 1.72 & 3.20 & 1.82 & 3.07 & 1.71 & 0.73 & 3.08 & 1.67 & 3.08 & 1.73 & 0.44 \\
\hline Planning & 2.58 & 1.67 & 3.07 & 1.77 & 2.53 & 1.65 & $13.08^{\star \star}$ & 2.11 & 1.49 & 2.68 & 1.69 & $19.25^{\star \star}$ \\
\hline Mental Disengagement & 2.23 & 1.53 & 1.86 & 1.41 & 2.27 & 1.53 & $10.43^{\star \star}$ & 1.98 & 1.38 & 2.28 & 1.55 & $5.30^{\star}$ \\
\hline Self-care & 1.93 & 1.46 & 1.96 & 1.64 & 1.93 & 1.44 & 0.01 & 1.46 & 1.10 & 2.03 & 1.50 & $21.34^{\star \star}$ \\
\hline Restraint Coping & 2.55 & 1.63 & 2.43 & 1.72 & 2.56 & 1.62 & 0.90 & 2.38 & 1.63 & 2.59 & 1.63 & $4.85^{\star}$ \\
\hline Seeking social support & 2.83 & 1.63 & 2.57 & 1.70 & 2.85 & 1.62 & $3.84^{\star}$ & 2.28 & 1.40 & 2.94 & 1.65 & $21.49^{\star \star}$ \\
\hline Behavioral Disengagement & 1.90 & 1.42 & 2.04 & 1.53 & 1.89 & 1.41 & 0.97 & 1.57 & 1.05 & 1.97 & 1.47 & $11.46^{\star \star}$ \\
\hline Acceptance & 3.56 & 1.50 & 3.71 & 1.34 & 3.54 & 1.50 & 2.39 & 2.73 & 1.57 & 3.72 & 1.44 & $60.91^{\star \star}$ \\
\hline Problem-Focused Coping & 2.75 & 1.15 & 2.77 & 1.29 & 2.75 & 1.14 & 0.37 & 2.44 & 0.96 & 2.82 & 1.18 & $18.89^{\star \star}$ \\
\hline Emotion-Focused Coping & 2.02 & 1.08 & 1.95 & 1.15 & 2.03 & 1.07 & 0.91 & 1.67 & 0.86 & 2.09 & 1.10 & $21.74^{\star \star}$ \\
\hline
\end{tabular}

Note: ${ }^{\star} p<0.05^{\star \star} p<0.01$. 
groups were of equal size. The overall $F$ values for both type of exposure and region ( $F=$ 1.649 and $F=1.298)$ were significant $(p<0.001)$.

\section{Posttraumatic distress (PTD)}

The mean IES-R-B score for the sample, as presented in Table III, was 1.62 (SD =1.06). About $14 \%$ of the sample reported a mean total IES-R-B of 2.0 or more indicating significant intensities of posttraumatic symptoms, and $1.7 \%$ of the sample reported an average score indicating severe posttraumatic symptomatology ( 3 or 4 on the 4-point Likert scale). Posttraumatic symptoms were higher among those who had been directly exposed to terror compared with those who had only been exposed indirectly. A similar picture emerged when high- versus low-impact regions were compared. Except for intrusion symptoms, which were similar across geographical sampling areas, individuals residing in high-impact regions reported more posttraumatic symptoms than those residing in the remote south. These results provide good support for our second and third hypotheses but indicate that distressful intrusive symptoms regarding terrorist violence were disturbing regardless of the area of residence. The posttraumatic distress variable (PTD) we created showed that at least one in every four Israelis may have suffered at least moderate levels of posttraumatic symptoms. Direct exposure to terrorism did not affect this variable, but individuals sampled from regions highly affected by terrorism were more troubled than individuals from less affected regions. The estimated mean prevalence of severe PTD (a possible equivalent of PTSD caseness) in connection with the 2001-2002 terrorism warfare against Israelis was $5.2 \%$. Although severe PTD seemed lower in the remote part of the country, none of our independent variables showed any significant effect.

\section{Coping tactics}

Table IV presents patterns of coping adopted by our respondents.

The most common way of coping among Israelis during the peak of the Al-Aqsa Intifada violence was: "I learned to live with the situation" $(M=3.56, \mathrm{SD}=1.51,58 \%),{ }^{1}$ reflecting a sense of acceptance of and adjustment to the uncontrollable perils of life under the threat of terror. The second most common way of coping was "I took direct action, for example: purchased a handgun"; this reflects a problem-focused, confrontive way of coping ( $\mathrm{M}=$ $3.08, \mathrm{SD}=1.72,48 \%)$. The next most frequently utilized coping strategy was "I spent more time with my friends or relatives" $(M=2.83 \mathrm{SD}=1.63,41 \%)$, reflecting an emotionfocused approach. The least used coping style was: "I turned to God, became more of a believer" ( $\mathrm{M}=1.83, \mathrm{SD}=1.49,25 \%)$.

Regardless of any particular way or category of coping, participants residing in the most harshly attacked locales employed coping behaviours more extensively than individuals sampled from a remote part of the country, thus lending support to our fourth hypothesis (e.g., problem-focused coping: $24 \%$ and $6 \%$ respectively). Table IV describes the differences in the ways of coping by level of personal exposure to terror and the region of residence. Although, the overall $\mathrm{F}$ value was significant $(\mathrm{F}=1.454 ; p<0.006)$, no significant differences in ways of coping were found between participants who had been directly exposed to terror and those who had not, thus no support was found for Hypothesis 5. Correlations between all variables under study are presented in Table V. The data show that the use of emotion- and problem-focused coping was associated with increased distress (higher negative mood and PTD scores). Acceptance, although unrelated to PTD, was beneficial because it was associated with improved mood (lower negative mood scores). 
Table V. Correlations between research variables $(N=327)$.

\begin{tabular}{|c|c|c|c|c|c|c|c|}
\hline & $\begin{array}{l}\text { Problem- } \\
\text { Focused } \\
\text { Coping }\end{array}$ & $\begin{array}{l}\text { Emotion- } \\
\text { Focused } \\
\text { Coping }\end{array}$ & Acceptance & Tension & Sadness & Avoidance & Intrusion \\
\hline Emotion-Focused Coping & $0.30^{\star \star}$ & & & & & & \\
\hline Acceptance & -0.02 & 0.10 & & & & & \\
\hline Tension & $0.34^{\star \star}$ & $0.17^{\star \star}$ & $-0.19^{\star \star}$ & & & & \\
\hline Sadness & $0.27^{\star \star}$ & $0.29^{\star \star}$ & $-0.14^{\star}$ & $0.47^{\star \star}$ & & & \\
\hline Avoidance & $0.29^{\star \star}$ & $0.41^{\star \star}$ & 0.07 & $0.13^{\star}$ & $0.25^{\star \star}$ & & \\
\hline Intrusion & $0.49^{\star \star}$ & $0.26^{\star \star}$ & 0.01 & $0.46^{\star \star}$ & $0.45^{\star \star}$ & $0.33^{\star \star}$ & \\
\hline Hyperarousal & $0.44^{\star \star}$ & $0.34^{\star \star}$ & 0.01 & $0.39^{\star \star}$ & $0.44^{\star \star}$ & $0.42^{\star \star}$ & $0.54^{\star \star}$ \\
\hline
\end{tabular}

Note: ${ }^{\star} p<0.05^{\star \star} p<0.01$.

\section{Discussion}

At the peak of a terror campaign, we assessed the effects of exposure, level of psychological distress and ways of coping among the Israeli public. Ten per cent of a randomly sampled group of respondents residing mostly in the hardest-hit heartland of Israel had been present on site when at least one of the attacks was perpetrated. The menacing hazard of terror, however, touched the lives of countless other citizens. About $28 \%$ of our respondents felt that they narrowly escaped an attack only by sheer luck. We feel this figure is a telling gauge of the sense of peril more than a quarter of our sample had experienced. This view is in line with data from the Herald of Free Enterprise disaster in the United Kingdom that showed how a catastrophe affected people who had personalized the event and thought of themselves as potential victims (Dixon, Rehling, \& Shiwach, 1993). The reality of the terror threat had become apparent very concretely to over one third of the participants in this study who had personally witnessed the devastation following one of the assaults on their community and to the $45 \%$ who had personally known somebody "who was there". The small geographical dimensions of the country probably explain the presence of survivors of terrorism in the group sampled from the remotest part of the state (but only some 270 miles to the south). This combined with the extensive and often graphic news coverage of breaking stories on terrorism must have contributed to the distress of individuals interviewed in parts of Israel that have never been exposed to terrorist violence directly.

Our index of negative mood (the $\mathrm{H}-\mathrm{MHI}$ ) describes a nation under a moderate level of emotional distress. A closer appraisal of the data revealed a total incidence of noteworthy sadness (scores of 4 or 5 on a 5-point scale) of about $18 \%$ among the population under study and a total incidence of noteworthy tension affecting every second citizen. These wide-spread levels of reported distress are consistent with those presented by Bleich et al. (2003), who stated that $58.6 \%$ of their sample reported feeling depressed and that $76.7 \%$ reported at least one traumatic stress symptom. There is evidence that persons directly affected by disasters have higher levels of post-event psychiatric disorders than persons indirectly affected (Green et al., 1990; North et al., 1999). Little is known, however, about the effects of repeated disasters on the mood of the general citizenry. National mood or demoralization in Israel appeared to be unrelated to the level of exposure to terrorism. Those who had been traumatized directly were no more likely to develop a negative mood than other citizens. Counter-intuitively, mood was not worse in the hardest-hit parts of the country but rather among the interviewees sampled from a remote desert region in Israel. The desert resort city of Eilat is a community inhabited by many transient tourism and entertainment workers who suffered severely from the terror-related tourism crisis. The town is much less cohesive as a society than the Israeli cities in the north. We posit that the 
national identification of our southern sample with the suffering in Israel's heartland, their exposure to media coverage of the events, combined with the economic crisis in this resort town and the lesser social solidarity and community cohesion there, may have contributed to this outcome.

As expected, posttraumatic stress symptoms, specifically symptoms of hyperarousal and avoidance, were more prevalent among those personally touched by terrorist violence and among residents of the hard-hit regions of the country. Individuals interviewed for this study who were residents of the remote southern region, however, were not less likely to develop intrusive posttraumatic symptoms than citizens of the north. A growing body of evidence documents a significant association between exposure to television coverage of catastrophic events and subsequent psychological symptoms (Cantor, Mares, \& Oliver, 1993; Pfefferbaum et al., 2001; Schuster et al., 2001). Although we did not measure television exposure in this study, it is conceivable that disturbing images of the devastation and human suffering aired by the national media added to the distress of inhabitants across the country. In our survey conducted at the height of the terror campaign $5.2 \%$ of a random sample of individuals residing mostly in the highly-affected areas reported symptoms consistent with a possible diagnosis of current PTSD. It is difficult to interpret this finding because of the uniqueness of the prolonged terrorism warfare Israelis have been exposed to and because our instrument was not specifically designed for clinical purposes; however, a comparable study identified $9.4 \%$ of an Israeli sample as meetings symptom criteria for PTSD (Bleich et al., 2003). In a recent article on PTSD in survivors of war or mass violence in four low-income countries, rates of PTSD were $37.4 \%$ in Algeria, $28.4 \%$ in Cambodia, $17.8 \%$ in Gaza, and $15.8 \%$ in Ethiopia (de Jong et al., 2001). These rates are considerably higher than data published on Americans: US population rates of PTSD were estimated to be $8 \%$ (Kessler, Sonnega, Bromet, \& Nelson, 1995), 3.6\% (Department of Health and Human Services, 1999) and 4\% (Schlenger et al., 2002). One suggested explanation for the high rate in Algeria was that the terrorist attacks were still ongoing when PTSD was assessed. The Israeli rate of severe PTD during the height of the terror campaign was not only lower than the comparable rates of PTSD measured in Algeria, another terror stricken country, but also lower than data collected in Manhattan weeks after the attack on the World Trade Center (7.5\%, Galea et al., 2002; 11.2\%, Schlenger et al., 2002). One explanation for this finding related to the different assessment procedures and inclusion criteria employed in the various studies. The Israeli scene, however, has provided a unique opportunity, for studying recurring stressful life events and their impact on coping with subsequent stressful conditions. Breznitz and Eshel (1983) suggested that although a higher baseline of pressures and stressors is characteristic of a large part of the Israeli population, the repeated exposure to intense stress can foster adequate modes of adjustment, based on learning from these experiences and subsequent habituation.

Some previous studies have found problem-focused coping to be at least minimally effective in their negative association with posttraumatic distress (e.g., Sharkasnky et al., 2000; Suvak, Vogt, Savarese, King, \& King, 2002). It would appear that both problem- and emotion-focused coping strategies employed by Israelis during the Intifada were consistently associated with high psychological distress, with the exception of Acceptance, which was the only strategy associated with better psychological outcome. Coping-outcome relationships may vary with the intensity of exposure. Problem-focused coping may be effective at moderate levels, but at low levels, it may be unnecessary, and at high levels, it may be irrelevant (Suvak et al., 2002). At the peak of a campaign of random terror, most ways of coping employed by Israelis failed to shield them from posttraumatic distress. 
In line with data presented by Charlton and Thompson (1996), it seems that the reappraisal of the situation and the distancing from its horrors associated with Acceptance was not only the most commonly used way of coping employed but also the only effective one.

This research project is among the few trauma-related stress studies that involved data collection during the acute stress stage (e.g., Bleich et al., 2003; Cohen Silver et al., 2002; Schuster et al., 2001; Shalev, Peri, Canetti, \& Schreiber, 1996; Somer et al., 1996). We also addressed several methodological limitations that have plagued previous research in the field. Samples of disaster studies have usually been small (Median for post disaster adjustment studies $=159$ ), demographically and ethnically homogeneous, and focused on non-minority middle-class respondents (Norris et al., 2002). Our study randomly sampled from low income rural towns and suburban areas and included Hebrew-speaking immigrant respondents. This study also has several limitations, however, that need to be considered when interpreting our results. First, we have no research data on the individuals we called who refused to participate in this study. Still the $60 \%$ response rate was not dissimilar from cooperation rates achieved in studies conducted in New York City after September 11 (70\%, Schlenger et al., 2002; 64\%, Galea et al., 2002). Second, this is a random sample. Even though our demographic data appear to be fairly representative of the Israeli adult population (Central Bureau of Statistics, 2002) it may not have been stratified enough to ensure optimal representation. A case in point is our exclusion of the few nonHebrew speaking respondents. Thus, some bias in our data should be taken into account. Third, although prior trauma and psychopathology can influence coping and posttraumatic symptoms, we did not measure prior traumatization and pre-existing mental health history. We felt that in our culture, such questions would have been too intrusive to use even in an anonymous telephone survey. To avoid significant drop-out and refusal rates and, in line with culture-sensitive research principles (e.g., Tillman, 2002), we decided to focus our questions on current terrorism threats. We were pleased that no consenting respondents dropped out during data collection, but we acknowledge that prior traumatization and preexisting psychopathology could have contributed to the reactivation of current distress among certain participants. Fourth, in a further effort to minimize respondent drop-out we decided to resort to brief or abbreviated research instruments. Some of these measures were rather less reliable than the full-length instruments. In addition, the coping tactics were assessed only with single items. Our results should be, therefore, interpreted cautiously and perhaps regarded as preliminary. These limitations may have harmed the interpretability and the generalizability of this field research.

To conclude, this investigation shows that the 2001-2002 terror campaign against Israel's heartland touched the lives of countless Israelis and negatively affected the general mood of many. Although citizens residing in the most severely hit locales were also those who suffered most from posttraumatic symptoms, the effects of major national trauma were not limited to those directly affected by it. These results are in line with outcomes obtained from a nationwide longitudinal study of psychological responses to September 11 (Cohen Silver et al., 2002) and suggest that objective measures of exposure or loss may not be sensitive predictors of reactive distress.

\section{Acknowledgements}

This study was partially supported by a grant from the R. D. Wolfe Centre for the Study of Psychological Stress, University of Haifa, Israel. The authors wish to thank Dvash Software Systems of Haifa, Israel for their kind assistance. 


\section{Note}

1 Items that received an endorsement score of 2 or above were counted as being employed at least to some degree.

\section{References}

Asch, D. A., Jedrziewski, M. K., \& Christakis, N. A. (1997). Response rates to mail surveys published in medical journals. Fournal of Clinical Epidemiology, 50, 1129-1136.

Berwick, D. M., Murphy, J. M., Goldman, P. A., Ware, J. E., Barsky, A. J., \& Weinstein, M. C. (1991). Performance of a five-item mental health screening test. Medical Care, 29, 169-176.

Billings, A. G., \& Moos, R. H. (1981). The role of coping responses and social resources in attenuating the stress of life events. Fournal of Behavioral Medicine, 4, 139-157.

Bleich, A., Gelkopf, M., \& Solomon, Z. (2003). Exposure to terrorism, stress-related mental health symptoms, and coping behaviors among a nationally representative sample in Israel. Fournal of the American Medical Association, 290, 612-620.

Breznitz, S., \& Eshel, Y. (1983). Life events: Stressful ordeal or valuable experiences? In S. Breznitz (Ed.), Stress in Israel (pp. 228-261). New York: Van Nostrand Reihhold.

Cantor, J., Mares, M. L., \& Oliver, M. B (1993). Parents' and children's emotional reactions to TV coverage of the Gulf War. In B. S. Greenberg, \& W. Gantz (Eds.), Desert Storm and the Mass Media (pp. 325-340). Cresskill, NJ: Hampton Press.

Carver, C. S., Scheier, M. F., \& Weintraub, J. K. (1989). Assessing coping strategies: A theoretically based approach. Fournal of Personality and Social Psychology, 56, 267-283.

Central Bureau of Statistics (2002). Statistical Abstract of Israel, Jerusalem: Central Bureau of Statistics. Accessed 10 March 2005, available at: http://www1.cbs.gov.il/reader/shnatonhnew.htm.

Charlton, P. F., \& Thompson, J. A. (1996). Ways of coping with psychological distress after trauma. British fournal of Clinical Psychology, 35, 517-530.

Cohen Silver, R., Holman, E. A., McIntosh, D. N., Poulin, M., \& Gil-Rivas, V. (2002). Nationwide Longitudinal Study of Psychological Responses to September 11. Fournal of the American Medical Association, 288, 12351244 .

de Jong, J., Komproe, I., Van Ommeren, M., El Masri, M., Araya, M., Khaled, N., van de Put, W., \& Somasundarum, D. (2001). Lifetime events and posttraumatic stress disorder in 4 postconflict settings. Fournal of the American Medical Association, 286, 555-562.

Department of Health and Human Services (1999). Mental health: a report of the Surgeon General. Rockville, MD: Substance abuse and Mental Health Services Administration, Center for Mental Health Services, National Institute for Mental Health.

Dixon, P., Rehling, G., \& Shiwach, R. (1993). Peripheral victims of the Herald of Free Enterprise disaster. British Fournal of Medical Psychology, 66, 193-202.

Folkman, S., \& Lazarus, R. S. (1980). An analysis of coping in a middle-aged community sample. Fournal of Health and Social Behavior, 21, 219-239.

Fouad, N. A. (1993). Cross-cultural vocational assessment. The Career Development Quarterly, 42, 4-13.

Galea, S., Ahren, J., Resnick, H., Kilpatrick, D., Bucuvalas, M., Gold, J., \& Vlahov, D. (2002). Psychological sequelae of the September 11 terrorist attacks in New York City. The New England fournal of Medicine, 346, 982-987.

Geisinger, K. F. (1994). Cross-cultural normative assessment: Translation and adaptation issues influencing the normative interpretation of assessment instruments. Psychological Assessment, 6, 304-312.

Gidron, Y. (2002). Posttraumatic stress disorder after terrorist attacks: A review. fournal of Nervous and Mental Disease, 190, 118-121.

Green, B., Grace, M., Lindy, J., Gleser, G. C., Leonard, A. C., \& Kramer, T. L. (1990). Buffalo Creek survivors in the second decade: Comparison with unexposed and nonlitigant groups. Fournal of Applied Social Psychology, 20, 1033-1050.

Hair, J. F. Jr., Anderson, R. E., Tatham, R. L., \& Clack, W. C. (1998). Multivariate Analysis (fifth edition). Upper Saddle River, NJ: Prentice Hall.

Hanley, J. A., \& McNeil, B. J. (1982). The meaning and use of the area under a receiver operating characteristic (ROC) curve. Radiology, 143, 29-36.

Hanley, J. A., \& McNeil, B. J. (1983). A method for comparing the areas under receiver operating characteristic curve derived from the same cases. Radiology, 148, 839-843.

Jeanrie, C., \& Bertrand, R. (1999). Translating Tests with the International Test Commission's Guidelines: Keeping Validity in Mind. European fournal of Psychological Assessment, 15, 277-283. 
Jenkins, S. R., \& Baird, S. (2002). Secondary traumatic stress and vicarious trauma: A validational study. Fournal of Traumatic Stress, 15, 423-432.

Kessler, R., Sonnega, A., Bromet, E., \& Nelson, C. (1995). Posttraumatic stress disorder in the National Comorbidity Study. Archives of General Psychiatry, 52, 1048-1060.

Krueger, R. A. (1994). Focus groups: A practical guide for applied research. Thousand Oaks, CA: Sage.

Lazarus, R. S. (1991). Emotion and Adaptation. Oxford: Oxford University Press.

Linhorst, D. M. (2002). A review of the use and potential of focus groups in social work research. Qualitative Social Work, 1, 208-228.

Lomranz, J., Hobfoll, S. E., Hohnson, R., Eyal, N., \& Zemach, N. (1994). A nation's response to attack: Israelis' depressive reactions to the Gulf War. Fournal of Traumatic Stress, 7, 59-73.

Lonner, W. J., \& Berry, J. W. (Eds.) (1986). Field methods in cross-cultural research. Beverly Hills, CA: Sage.

Marmar, C. R., Weiss, D. S., Metzler, T. J., Ronfeldt, H. M., \& Forman, C. (1996). Stress responses of emergency services personnel to the Loma Prieta earthquake interstate 880 freeway collapse and control traumatic incidents. Fournal of Traumatic Stress, 9, 63-85.

Moos, R. H., \& Billings, A. G. (1982). Conceptualizing and measuring coping resources and processes. In L. Goldberger, \& S. Bresnitz (Eds.), Handbook of stress: Theoretical and clinical aspects (pp. 212-230). New York: The Free Press.

Morgan, L. D. (1988). Focus groups as qualitative research. Newbury Park, CA: Sage Publications.

Norris, F. H., Friedman, M., Watson, P., Byrne, C., Diaz, E., \& Kaniasty, K. (2002). 60,000 disaster victims speak: Part I. An empirical review of the empirical literature, 1981-2001. Psychiatry, 65, 207-223.

North, C. S., \& Pfefferbaum, B. (2002). Research on the mental health effects of terrorism. Fournal of the American Medical Association, 288, 633-636.

North, C. S., Nixon, S. J., Shariat, S., Mallonee, S., McMillen, J. C., Spitznagel, E. L., \& Smith, E. M. (1999). Psychiatric disorders among survivors of the Oklahoma City bombing. Fournal of the American Medical Association, 282, 755-762.

Parker, J. D. A., \& Endier, N. S. (1992). Coping with coping assessment: A critical review. European fournal of Personality, 6, 321-344.

Pfefferbaum, B., Moore, V., McDonald, N., Maynard, B., Gurwitch, R., \& Nixon, S. (1999). The role of exposure in posttraumatic stress in youths following the 1995 bombing. Fournal of the State Medical Association, 92, 164167.

Pfefferbaum, B., Nixon, S., Tivis, R., Doughty, D., Pynoos, R., Gurwitch, R., \& Foy, D. (2001). Television exposure in children after a terrorist incident. Psychiatry, 64, 202-211.

Pfefferbaum, B., Nixon, S., Tucker, P., Tivis, R., Morre, V., Gurwitch, R., Pynoos, R., \& Geis, H. (1999). Posttraumatic stress response in bereaved children after the Oklahoma City bombing. Fournal of the American Academy of Child and Adolescent Psychiatry, 38, 1372-1379.

Resnick, H., Kilpatrick, D., Dansky, B., Saunders, B., \& Best, C. (1993). Prevalence of civilian trauma and posttraumatic stress disorder in a representative national survey of women. Fournal of Consulting and Clinical Psychology, 61, 984-991.

Schlenger, W. E., Caddell, J. M., Ebert, L., Jordan, B. K., Rourke, K. M., Wilson, D., Thalji, L., Dennis, J. M., Fairbank, J. A., \& Kulka, R. A. (2002). Psychological reactions to terrorist attacks: findings from the National Study of Americans' Reactions to September 11. Fournal of the American Medical Association, 288, 581588.

Schuster, M. A., Stein, B. D., Jaycox, L., Collins, R. L., Marshall, G. N., Elliott, M. N., Zhou, A. J., Kanouse D. E., Morrison, J. L., \& Berry, S. H. (2001). A national survey of stress reactions after the September 11, 2001, terrorist attacks. New England fournal of Medicine, 345, 1507-1512.

Shalev, A. Y., Peri, T., Canetti, L., \& Schreiber, S. (1996). Predictors of PTSD in injured trauma survivors: A prospective study. American fournal of Psychiatry, 153, 219-225.

Sharkansky, E. J., King, D. W., King, L. A., Wolfe, J., Erikson, D. J., \& Stokes, L. R. (2000). Coping with Gulf War combat stress: Mediating and moderating effects. Fournal of Abnormal Psychology, 109, 188-197.

Smith, W., Chey, T., Jalaludin, B., Salkeld, G., \& Capon, T. (1995). Increasing response rates in telephone surveys: a randomized trial. Fournal of Public Health Medicine, 17, 33-38.

Somer, E., Keinan, G., \& Carmil, D. (1996). Psychological adaptation of anxiety disorder patients following repeated exposure to emergency situations. Fournal of Traumatic Stress, 9, 207-221.

Somer, E., Soref, E., \& Lawental, E. (2004). Dissociative disorders among individuals with opiate use disorder: A research report. Jerusalem: The Israel Anti-drug Authority (In Hebrew).

Spradely, J. P. (1979). The ethnographic interviews. New York: Holt, Hinehart \& Winston.

Stewart, D., \& Shamdasani, P. (1990). Focus groups: Theory and practice. Newbury Park, CA: Sage. 


\section{E. Somer et al.}

Suvak, M. K., Vogt, D. S., Savarese, V. W., King, L. A., \& King, D. W. (2002). Relationship of war-zone coping strategies to long-term general life adjustment among Viet-nam veterans: Combat exposure as a moderator variable. Personality and Social Psychology Bulletin, 28, 974-985.

Tillman, L. C. (2002). Culturally Sensitive Research Approaches: An African-American Perspective. Educational Researcher, 31 (9), 3-12.

Weiss, D. S., Marmar, C. R., Metzler, T. J., \& Ronfeldt, H. M. (1995). Predicting symptomatic distress in emergency services personnel. Fournal of Consulting and Clinical Psychology, 63, 361-368.

Weiss, D., \& Marmar, C. (1997). The Impact of Event Scale -Revised. In J. Wilson, \& T. Keane (Eds.), Assessing psychological trauma and PTSD. New York: Guildford.

Yagur, A., Grinshpoon, A., \& Ponizovsky, A. (2002). Primary clinic attendees under war stress. Israel Medical Association fournal, 4, 568-572. 